\title{
The Journal of Hematopathology: a new adventure!?
}

\author{
J. Han J. M. van Krieken
}

Published online: 18 July 2008

(C) Springer-Verlag 2008

This is the first issue of the new Journal of Hematopathology. The immediate question that arises is: why do we need another journal? The topics hematopathologists deal with are already covered by many journals, like the American Journal of Surgical Pathology, Histopathology, Blood, Leukemia, and various others. But, that is also the issue: It is not easy to keep up to date with the broad field of hematopathology, which covers diseases of the lymphoid organs, including the bone marrow, and deals with morphology, immunohistochemistry, and molecular techniques. The aim of the new journal is to bring the different developments together in one journal, so that the practicing hematopathologist is able to keep up with the variety of new development in the field. The journal will therefore contain reviews, case studies, and research articles varying from molecular studies to clinic-pathological correlations.

Important for a new journal is the quality of the associated editors, Juddy Ferry (USA), Leticia Quintanilla-Fend (Germany), John Chan (Hong Kong), Fernando Soares (Brazil), and David Ellis (Australia), and the editorial board.

K. Aozasa, Osaka, Japan

O. Balagué, Barcelona, Spain

C. Bueso-Ramos, Houston, USA

A.C.L. Chan, Kowloon, Hong Kong

W. Cheuk, Kowloon, Hong Kong

D. de Jong, Amsterdam, The Netherlands

L. de Leval, Liège, Belgium

F. Fend, Tuebingen, Germany

R.F. Franco, São Paulo, Brazil

R.P. Hasserjian, Boston, USA

K.M. Hebeda, Nijmegen, The Netherlands

W. Klapper, Kiel, Germany

J. H. J. M. van Krieken $(\bowtie)$

Department of Pathology,

Radboud University Nijmegen, Medical Centre,

Postbus 9101,

6500 HB Nijmegen, The Netherlands

e-mail: J.vanKrieken@pathol.umcn.nl
Y.-H. Ko, Seoul, South Korea

L. Leoncini, Siena, Italy

C. Lome Maldonado, Tlalpan, Mexico

J. Miliauskas, Wayville, South Australia, Australia

J.C. Morais, Niterói, Rio de Janeiro, Brazil

P.L. Nguyen, Rochester, USA

D. Norris, West End, Queensland, Australia

G. Ott, Stuttgart, Germany

S.-C. Pej, Kuala Lumpur, Malaysia

F.I. Preffer, Boston, USA

D. Spagnolo, Nedlands, Western Australia, Australia

S. Swain, Prahran, Victoria, Australia

J. Turner, Darlinghurst, Australia

C. van Vliet, Grafton, Auckland, New Zealand

J. Vassallo, Campinas, Brazil

A. Vijnovich-Baron, Buenos Aires, Argentina

L. Zukerberg, Boston, USA

Together, they form a group of distinguished hematopathologists, with varying scope and expertise, from molecularly oriented academic researchers, to practicing non-academic colleagues, and a team covering a wide area of the world.

The Journal of Hematopathology is at its start a free, open-access online-only journal, although occasionally printed volumes will appear. We intend to print the second issue in association with the abstracts of the European Association of Hematopathology meeting in Bordeaux. The journal aims for a fast review cycle and aims to have articles online on short notice.

Hematopathology is a rapidly evolving field of pathology in which changes take place all the time. This year the new World Health Organization classification is to be expected with further impact of techniques to be used in conjunction with tissue diagnosis. The journal hopes to serve as a guide by which choices on ancillary techniques can be made. We hope you will enjoy reading this first issue!

Han van Krieken

Editor-in-Chief 